\title{
Papers
}

\section{Systematic comparison of four sources of drug information regarding adjustment of dose for renal function}

Liat Vidal, Maya Shavit, Abigail Fraser, Mical Paul, Leonard Leibovici

\begin{abstract}
Objective To compare advice on dosage adjustment for renal impairment provided by four commonly used secondary pharmacotherapeutic sources.

Design Systematic comparison of the definitions of renal impairment, recommendations for dosage adjustment, and the evidence in support of these recommendations in four information sources.

Data sources British National Formulary, Martindale: the Complete Drug Reference, American Hospital Formulary System Drug Information, and Drug Prescribing in Renal Failure.

Review methods Two reviewers independently extracted data on recommendations for dosage adjustment for impaired renal function of 100 drugs often used in our hospital.

Results The four sources differed in their recommendations for adjustments of dosage and dosing interval. They vary in their definitions of renal impairment; some are qualitative and remain unclear. All sources provide only a general description; the methods on which the advice is based and references for original data are rarely presented.

Conclusions The remarkable variation in definitions and recommendations, along with scarce details of the methods used to reach this advice, makes the available sources of drug information ill suited for clinical use. The methods used to retrieve information and use data should be described and made available to the reader. Advice on drug prescription, dose and dosing interval, contraindications, and adverse effects should be evidence based.
\end{abstract}

\section{Introduction}

Many drugs and their metabolites are excreted through the kidneys. When renal function is impaired, the dosage or the dosing interval should be adjusted for some drugs. In an attempt to reduce medication errors by using computerised decision support (www.amica-eu.org) we compiled an explicit list of drugs that need adjustment for impaired renal function for use in our hospital and specified the needed adjustment.

We originally intended to use the British National Formulary as the primary source, ${ }^{1}$ but for many drugs the $B N F$ gave only a general warning, without explicit advice on how to adjust the dose or dosing interval. We consulted three other secondary sources of pharmacotherapy that are used in our hospital: Martindale: the Complete Drug Reference, ${ }^{2}$ American Hospital Formulary System (AHFS) Drug Information, ${ }^{3}$ and Drug Prescribing in Renal Failure. The extent of information in the four sources varied, and discrepancies between their recommendations were soon evident. In order to decide on a source (or sources) to use, we compared the four sources.

\section{Methods}

To perform a systematic comparison of four sources of information on drugs we identified the definitions that our four sources used for renal impairment, the drugs that are marked for dosage or interval adjustment for impaired renal function, and the evidence that the four sources quote in support of their recommendations. In cases of major discrepancies between sources we searched Medline to look for supporting data. Two reviewers (LV, MS) independently extracted data and settled disagreements by discussion with a third reviewer (MP).

We extracted data for 100 drugs that were most often prescribed in our hospital during 2003, judging by the defined daily dose (DDD) consumption (DDD is the assumed average maintenance dose per day for a drug used for its main indication in adults; see bmj.com).

\section{Results}

The definitions used by the four sources differed in several respects. Two of the sources (Martindale and AHFS Drug Information) use qualitative terms for renal function and impairment, without defining them (box). The other two sources use explicit but different definitions: the $B N F$ uses a category of moderate renal impairment, glomerular filtration rate of 10-20 $\mathrm{ml} /$ minute, which is missing from the definition used in Drug Prescribing in Renal Failure. This difference is not a minor one. The prevalence of this category in adults with chronic renal failure is about $5 \% .^{5}$

All sources provide only general information on their decision making process regarding adjustments for renal function. This information is not detailed enough to help users reach primary sources or reconstruct the process (see bmj.com).

The different sources expressed recommendations in quantitative and qualitative terms. None of the qualitative terms is defined. We grouped the terms into several categories (table 1) to compare them.

We also looked at the references quoted to support recommendations. The $B N F$ cited no references, and the practice of the other three sources varied (table 2).

A list of 100 drugs most commonly used at Rabin Medical Center and descriptions of the process and use of sources to reach recommendations are on bmj.com 


\begin{tabular}{|c|c|c|c|c|}
\hline Category & British National Formulary & Martindale & AHFS Drug Information 2004 & Drug Prescribing in Renal Failure \\
\hline Q: Quantitative recommendations: & $\begin{array}{l}\text { Initial dose } \\
\text { Maximal dose } \\
\text { Specific dose }\end{array}$ & $\begin{array}{l}\text { Initial dose } \\
\text { Maximal dose } \\
\text { Loading dose } \\
\text { Specific dose }\end{array}$ & $\begin{array}{l}\text { Initial dose } \\
\text { Maximal dose } \\
\text { Specific dose }\end{array}$ & $\begin{array}{l}\text { Initial dose } \\
\text { Maximal dose } \\
\text { Specific dose }\end{array}$ \\
\hline $\begin{array}{l}\text { NQ: Non-quantitative } \\
\text { recommendations: }\end{array}$ & $\begin{array}{l}\text { Start with small doses } \\
\text { Avoid or use small dose } \\
\text { Reduce dose } \\
\text { Use lowest effective dose } \\
\text { May need low/high doses } \\
\end{array}$ & $\begin{array}{l}\text { May require reduced doses } \\
\text { Should be used with caution or in } \\
\text { reduced doses } \\
\text { The dosage may need to be adjusted }\end{array}$ & $\begin{array}{l}\text { Reduced dosage may be considered } \\
\text { Adjust dosage carefully }\end{array}$ & \\
\hline V: Avoid & $\begin{array}{l}\text { Avoid } \\
\text { Avoid if possible } \\
\text { Avoid routine use } \\
\text { Avoid or reduce dose }\end{array}$ & $\begin{array}{l}\text { Avoid } \\
\text { Do not give } \\
\text { Should not be used } \\
\text { Considered by some contraindicated }\end{array}$ & $\begin{array}{l}\text { Avoid } \\
\text { Do not use } \\
\text { Contraindicated }\end{array}$ & Avoid \\
\hline C: Use with caution & $\begin{array}{l}\text { Caution } \\
\text { Manufacturer - caution } \\
\text { Risk of adverse effects increased }\end{array}$ & $\begin{array}{l}\text { Caution } \\
\text { Use with care } \\
\text { Use with considerable care } \\
\text { Use with caution or not at all }\end{array}$ & $\begin{array}{l}\text { Caution } \\
\text { Manufacturer-caution } \\
\text { Extreme caution } \\
\text { Use with extreme caution if at all } \\
\text { Monitor parameters } \\
\text { Excessive adverse effects }\end{array}$ & Metabolites can accumulate \\
\hline
\end{tabular}

\section{Recommendations and comparisons}

The $B N F$ recommends some form of adjustment for impaired renal function for 51 drugs (54\%), Martindale for 62 drugs (62\%), AHFS Drug Information for 50 drugs (56\%), and Drug Prescribing in Renal Failure for 36 drugs (53\%). Precise recommendations (numerical adjustment or avoid) were advised for 25 drugs in the

\section{Categories of renal impairment for dose or interval adjustment in the four sources}

British National Formulary

Renal impairment is defined by glomerular filtration rate (numerical values) and divided into four grades:

Greater than $50 \mathrm{ml} / \mathrm{min}$

Mild: $20-50 \mathrm{ml} / \mathrm{min}$

Moderate: $10-20 \mathrm{ml} / \mathrm{min}$

Severe: $0-10 \mathrm{ml} / \mathrm{min}$

Martindale: the Complete Drug Reference

The following terms are used without definitions:

Severe, chronic renal insufficiency

Renal insufficiency

Renal impairment

Moderate-severe renal failure

Chronic renal failure

(Glomerular filtration rate values are without predefined categories.)

AHFS Drug Information 2004

The following terms are used without definitions:

Renal impairment

Advanced chronic renal insufficiency

Renal insufficiency, severe

Substantially impaired renal function

Renal disease

(Glomerular filtration rate values are without predefined categories.)

Drug Prescribing in Renal Failure

Renal function is defined by glomerular filtration rate (numerical values) and divided into three grades:

Greater than $50 \mathrm{ml} / \mathrm{min}$

$10-50 \mathrm{ml} / \mathrm{min}$

Less than $10 \mathrm{ml} / \mathrm{min}$
BNF, 34 in Martindale, 23 in AHFS Drug Information, and 35 in Drug Prescribing in Renal Failure (table 3).

We further examined how drugs that required no adjustment according to one source were categorised by a second source (table 4). The differences were remarkable-for example, 11 drugs $(26 \%)$ out of 43 for which the $B N F$ recommended no adjustment were categorised by Martindale as requiring it (dexamethasone, prednisone, methylprednisolone, hydrocortisone, paracetamol, amiodarone, promethazine, isosorbide mononitrate, isosorbide dinitrate, progesterone, loratadine). We also looked for information on the need to adjust dosage according to renal function by searching Medline, combining the names of the 11 drugs with the MESH terms for kidney failure, glomerular filtration rate, pharmacokinetics, and adverse events. We attained helpful articles for only five drugs (paracetamol, amiodarone, isosorbide dinitrate, loratadine, and promethazine).

In seven instances (six drugs) a drug that required no adjustment according to one source was categorised as contraindicated in patients with impaired renal function by a second source (table 4).

\section{Discussion}

Recommendations on dosage adjustment for renal impairment in sources that are considered reliable and are in common use were often worded in qualitative and undefined terms, ill suited for practical use. The variation between sources was remarkable, including drugs for which no adjustment was recommended in one source while another marked them as contraindicated in renal failure. Some variation is to be expected as a matter of interpretation. However, clinicians are given nearly no evidence in support of recommendations and thus gain little insight into the sources of the contradiction. Only a general description of the process used to reach recommendations is provided, or none at all. Three out of the four secondary sources give no or little reference to primary sources. ${ }^{1-3}$ A thorough (but not exhaustive) search of Medline failed to find primary sources for some drugs for which contradictory advice was offered. It is difficult to imagine that a clinician could perform a more comprehensive search, considering time constraints. Given the contradictions between sources and lack of primary references, judging how much these secondary sources of drug information can be relied on is also difficult. 
Table 2 References quoted by the four sources to support recommendations for renal adjustment in 100 drugs

\begin{tabular}{|c|c|c|c|c|}
\hline Category of reference & $\begin{array}{c}\text { British National } \\
\text { Formulary }\end{array}$ & Martindale & AHFS Drug Information 2004 & Drug Prescribing in Renal Failure \\
\hline No references & 94 & 80 & 75 & 6 \\
\hline Pharmacokinetic studies & 0 & 16 & 1 & 51 \\
\hline Supplied by the manufacturer & 0 & 2 & 13 & 0 \\
\hline Case reports, anecdotes, narrative reviews & 0 & 2 & 0 & 11 \\
\hline Systematic reviews, trials, cohort studies & 0 & 0 & 0 & 0 \\
\hline Drugs not included & 6 & 0 & 10 & 32 \\
\hline
\end{tabular}

\section{Limitations of the study}

Our analysis is limited by several factors. We looked at only four secondary sources of information in common use in our hospital and health maintaining organisation (Clalit Health Services), but the chance that more sources will reduce the variability between sources is small. We based our comparison on 100 drugs that are consumed most often in our hospital. We have little reason to assume that the choice was biased and included problematic drugs. We tackled only adjustments for renal impairment, but we can guess that the adjustment for liver failure, for example, is no better described or referenced.

\section{Conclusions}

Looking for evidence on the efficiency of interventions, clinicians are taught to expect secondary sources (for example, systematic reviews in the Cochrane Library) to use their primary sources in a methodical manner: transparent and reproducible workflow, a thorough and explicit search for references, elimination of bias, and a short description of the primary sources. What should clinicians (and their patients) expect from a reliable secondary source of drug information? The methods used to retrieve information and data on use should be described and made available to the reader-for example, which kind of data are solicited from the manufacturer, how their reliability is judged, and how the data are translated into quantitative recommendations. Readers should be told if other sources of primary information are searched, which methods are used to search them, and again how the information is translated into recommendations. Primary data should be summarised, and the reader should have easy access to it. If possible, quantitative recommendations on dosages and dosing intervals should be made. If not, the reason for the qualitative recommendation should be made clear. The basics of drug prescription-dosage and dosing interval, contraindications, and expected adverse effects-should be no less evidence based than the efficacy and effectiveness of a drug or intervention.

Contributors: LV, MS, and LL had the idea for the article. LV, MS, AF, and MP performed searches and data collection. LV and LL wrote the article and are guarantors.

Funding: EC 6th Framework IST grant, AMICA, contract number 507048. Competing interests: None declared.

Ethical approval: Not required.

1 Joint Formulary Committee. British national formulary. 48th ed. London: British Medical Association and Royal Pharmaceutical Society of Great Britain, 2004. cal Association and Royc

2 Sweetman SC, ed. Martindale: the complete drug reference. London: Pharmaceutical Press, 2004.

3 In: McEvoy GK, Miller J, Snow EK, Welsh OH, Litvak K, eds. American Hospital (AHFS) drug information 2004. Bethesda: American Society of Health-System Pharmacists, 2004.

4 Aronoff GR, Berns JS, Brier ME, Golper TA, Morrison G, Singer I, et al, eds. Drug prescribing in renal failure: dosing guidelines for adults. Philadelphia: American College of Physicians, 1999.

5 Jones CA, McQuillan GM, Kusek JW, Eberhardt MS, Herman WH, Coresh J, et al. Serum creatinine levels in the US population: third national health and nutrition examination survey. Am J Kidney Dis 1998;32:992-9.

(Accepted 27 April 2005)

doi $10.1136 /$ bmj.38476.471088.3A

Table 3 Category of renal adjustment for 100 drugs according to the four sources

\begin{tabular}{|c|c|c|c|c|}
\hline Category & $\begin{array}{c}\text { British National } \\
\text { Formulary }\end{array}$ & Martindale & AHFS Drug Information 2004 & Drug Prescribing in Renal Failure \\
\hline Q: Quantitative recommendations & 11 & 22 & 18 & 29 \\
\hline NQ: Non-quantitative recommendations & 21 & 12 & 6 & 0 \\
\hline V: Avoid & 14 & 12 & 6 & 6 \\
\hline C: Use with caution & 5 & 16 & 21 & 1 \\
\hline $\mathrm{N}$ : Adjustment not needed & 43 & 38 & 39 & 32 \\
\hline Drugs not included & 6 & 0 & 10 & 32 \\
\hline
\end{tabular}

Table 4 Drugs for which no adjustment was recommended: how were they classified in the other sources

\begin{tabular}{|c|c|c|c|c|c|c|c|c|c|c|c|c|c|c|c|c|}
\hline \multirow{2}{*}{$\begin{array}{l}\text { Source in which no } \\
\text { adjustment was required }\end{array}$} & \multicolumn{4}{|c|}{ British National Formulary } & \multicolumn{4}{|c|}{ Martindale } & \multicolumn{4}{|c|}{ AHFS Drug Information 2004} & \multicolumn{4}{|c|}{ Drug Prescribing in Renal Failure } \\
\hline & M & $\mathbf{N}$ & a & V & M & $\mathbf{N}$ & a & V & M & $\mathbf{N}$ & $\mathbf{a}$ & $\mathbf{v}$ & M & $\mathrm{N}$ & a & V \\
\hline $\begin{array}{l}\text { British National Formulary } \\
(\mathrm{n}=43)\end{array}$ & - & - & - & - & 0 & 32 & 11 & 0 & 6 & 30 & 7 & 0 & 22 & 17 & 3 & $1^{*}$ \\
\hline Martindale $(n=38)$ & 1 & 32 & 4 & $1 \dagger$ & - & - & - & - & 5 & 30 & 3 & 0 & 22 & 13 & 2 & $1^{*}$ \\
\hline $\begin{array}{c}\text { AHFS Drug Information } \\
2004(\mathrm{n}=39)\end{array}$ & 0 & 33 & 5 & $1 \ddagger$ & 0 & 31 & 8 & 0 & - & - & - & - & 18 & 16 & 4 & $1^{*}$ \\
\hline Drug Prescribing in Renal & 0 & 17 & 13 & $2 \S$ & 0 & 13 & 17 & $2 \pi$ & 1 & 16 & 15 & 0 & - & - & - & - \\
\hline
\end{tabular}

Failure $(\mathrm{n}=32)$

$\mathrm{M}=$ missing. $\mathrm{N}=\mathrm{no}$ adjustment required. $\mathrm{Q}=$ adjustment required (includes $\mathrm{Q}$ : quantitative recommendations, $\mathrm{NQ}$ : non-quantitative recommendations, and $\mathrm{C}$ : use with caution). V=contraindicated/ avoid

${ }^{*}$ Terbutaline.

†Lercanidipine.

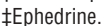

$\S N a p r o x e n$, warfarin.

IHeparin, warfarin. 


\section{What is already known on this subject}

The dosage of many drugs should be adjusted when prescribed to patients with renal impairment

Data on the adjustment of the dose or dosing interval are available in several secondary pharmacotherapeutic sources

\section{What this study adds}

Sources of drug information vary in their definitions and recommendations

The methods and primary sources used to reach these recommendations are not described
Department of Medicine E, Beilinson Campus, Rabin Medical Center, Petah-Tiqva, Israel

Liat Vidal physician, research unit

Maya Shavit pharmacist, research unit

Abigail Fraser head of research unit

Mical Paul attending physician

Leonard Leibovici head of department

Correspondence to: L Leibovici leibovic@post.tau.ac.il 